\title{
Cost Analysis of a Prehabilitation Program in High-risk Patients Undergoing Elective Major Abdominal Surgery
}

Manuel López-Baamonde1, D. Sánchez Barcenilla1 , M. Ubré1, A. Barberán-García², D. Capitán1, G. Martínez-Pallí1

${ }^{1}$ Anaesthesiology Department, Hospital Clínic de Barcelona - Barcelona (Spain)

${ }^{2}$ Respiratory Clinic Institute. Institut d'Investigacions Biomèdiques August Pi i Sunyer (IDIBAPS) - Barcelona (Spain)

\section{Background}

Preoperative personalized programs (prehabilitation) are effective in reducing postoperative complications in high-risk patients undergoing major abdominal surgery. However, its effects on healthcare costs are still unknown.

\section{Objective}

To assess the impact of a personalized prehabiltation program in high-risk patients undergoing major abdominal surgery on costs from a hospital perspective.

\section{Methods}

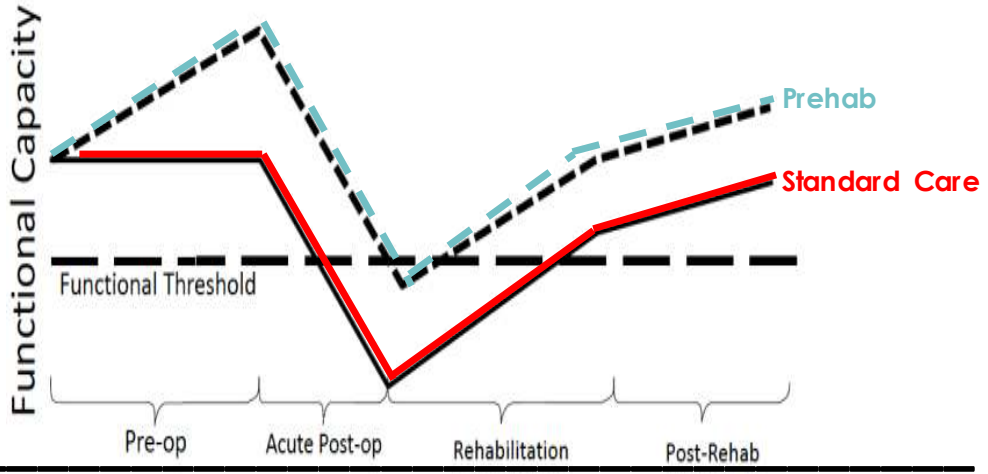

This study involved data arising from a previously published randomized controlled trial which demonstrated the efficacy of prehabilitation versus standard c are in reducing postoperative complications in high-risk undergoing major abdominal surgery (Barberan-Garcia A, et al. Ann Surg 2017). The costs of the prehabilitation program and hospital resources related to surgery were also eval uated. The cost analysis was performed for all of the patients with the support of the financial department of our hospital.

Prehabilitation program costs included: i) a cardiopulmonary exercise testing; ii) the physiotherapist fees (group training sessions); iii) a pedometer device: and, iv) a motivational interviewing.

Hospitalization costs after surgery included: i) inpatient services, ii) diagnostic procedures, iii) pharmaceutical consumption, iv) blood products consumption; and, v) structural costs.

Costs of surgery and use of the operating room were not taken into account. Separate analysis including 30-day readmissions and excluding outliers were also performed. Mean savings of the prehabilitation program (differential costs = control group - prehab group) and Cl95\% were computed with bootstrapping (1,000 replications).

\section{Results}

One-hundre dand twenty-five patients (63 control and 62 intervention), out of the 144 participating in the study, were finally included in the intention-totreat analysis.

The prehabilitation program cost was 389 euros per patient (table 1).

The average hospital costs per patient in the prehabilitation group were $€ 4,340$ and in the control group were $€ 7,643$ ( $p=0.134$ ). The control group has two outliers (graphic 1).

The impact of the prehabilitation in comparison with standard care represented a mean saving of (table 2):

- 3,659€ per patient (95\% IC EUR -36 to 8,459€) taking in account the whole sample and the 30-day readmission costs.

- $757 €$ per patient ( $95 \%$ IC EUR -880 to $2,583 €$ ) taking in account the reduced sample (removing the outliers) and the readmission costs.

Table 1: Prehabilitation program costs

\begin{tabular}{|l|c|}
\hline CPET & $203 €$ \\
\hline Physiotherapist Fees & $96 €$ \\
\hline Pedometer Device & $22 €$ \\
\hline Motivational Interviewing & $41 €$ \\
\hline Total & $389 €$ \\
\hline
\end{tabular}

Table 2: Mean saving of the prehabilitation program

\begin{tabular}{|c|c|c|}
\hline & $\begin{array}{c}\text { Whole sample } \\
\mathbf{n}=\mathbf{1 2 5}\end{array}$ & $\begin{array}{c}\text { Reduced sam ple } \\
\mathbf{n}=\mathbf{1 2 3}\end{array}$ \\
\hline $\begin{array}{c}\text { WITHOUT } \\
\text { Readmission costs }\end{array}$ & $3,254 €$ & $333 €$ \\
$\begin{array}{c}\text { WITH } \\
\text { 30-299 } €-8,011 €)\end{array}$ & $(-1,010 €-1,934 €)$ \\
$\begin{array}{c}\text { 30y readmission } \\
\text { costs }\end{array}$ & $3,659 €$ & $\mathbf{7 5 7} €$ \\
$(-36 €-8,459 €)$ & $(-880 €-2,583 €)$ \\
\hline
\end{tabular}

$\mathrm{N}$

Graphic 1. Histogram of Hospitalization Costs After Surgery

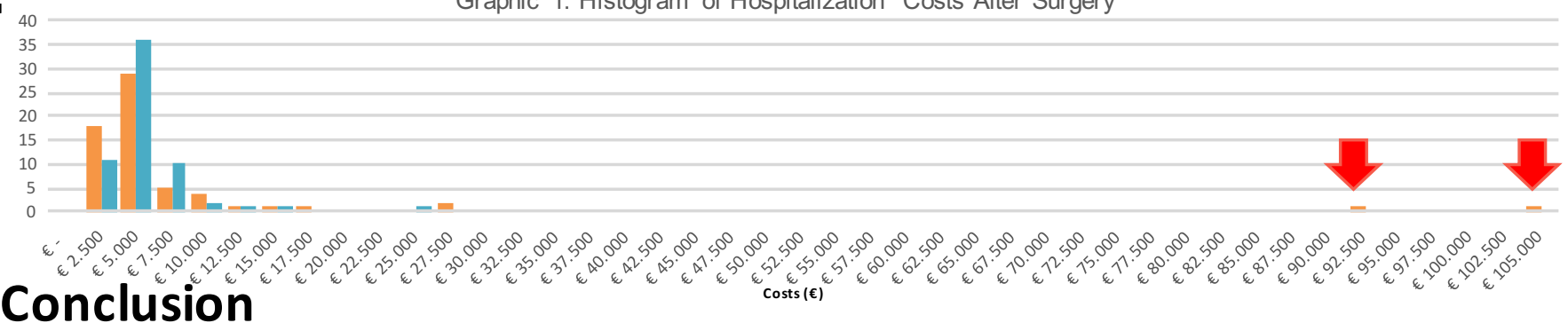

Preh abilitation showed positive mean savings compared to st andard care for high-risk patients in major abdomin al surg ery but results were not statistically significant. A larger sample size may have resulted in a statistically significant result. 